ISSN: 0213-2079 - ISSN electrónico: 2386-3889

DOI: https://doi.org/10.14201/shhmo2019411231258

\title{
¿UN PUEBLO IGNORANTE DE SU DEBER? EL 'ESTADO CONFESIONAL’ DE INGLATERRA Y LAS LIMITACIONES ESTRATÉGICAS EN LA ÉPOCA DE CHARLES I Y OLIVER CROMWELL
}

\section{A people so ignorant of their duty? The English 'confessional state' and strategic limitations in the time of Charles I and Oliver Cromwell}

\section{Phillip WILLIAMS}

Sino-British College

University of Shanghai for Science and Technology

Correo-e: drphillipjohn@icloud.com; phillip.williams@sbc.usst.edu.cn

RESUMEN: En el Seiscientos, el gobierno de Londres no disponía de los recursos de Madrid, Paris o Ámsterdam, cuyas capacidades militares estaban muy por encima de las de los reyes Stuart y Oliver Cromwell. Por esta razón, siempre existió una contradicción entre la proyección de un estado confesional y las realidades de un gobierno con capacidades muy restringidas para afrontar la guerra. Esta perspectiva se ha manifestado en el revisionismo, que ha puesto en cuestión muchas de las viejas certidumbres sobre el papel del Parlamento y los «puritanos». Eminentes historiadores han alegado que la causa - la única causa - de la Guerra Civil (1642-1646) fue Charles I (1625-1649), su programa confesional y sus múltiples maniobras y artimañas. El verdadero cambio no llegó hasta después de 1688, cuando se produjo una mutación profunda en la trayectoria del estado. Esta visión de la historia de Inglaterra cuadra bien con los intentos de cuestionar, y aun abandonar, modelos como los de «revolución militar», «absolutismo» $\mathrm{y}$ «mercantilismo».

Palabras clave: Revolución militar; estado dinástico; estado confesional; parlamento; guerra civil inglesa; Charles I de Inglaterra; Oliver Cromwell. 
ABSTRACT: Set in a comparative context alongside Madrid, Paris or Amsterdam, the English crown was certainly extremely short of resources in the first half of the seventeenth-century. Indeed, even after the Restoration (1660) the crown was faced with a financial deficit that placed enormous restrictions on the use of the fleet. There was, therefore, always an enormous contradiction between the projection of a confessional state and the realities of a government whose ability to finance war was highly limited. This perspective has emerged in a revisionism which has questioned the old orthodoxy on the role of parliament and the "puritans». Revisionist historians tend to see Charles I, his confessional programme, deceptions and betrayals as the cause of the Civil War (1642-1646) - often, indeed, as its only cause. Many argue that the real change emerged after 1688, when the political economy of the state was transformed. This vision dovetails with efforts to question, or even abandon, concepts such as the «military revolution», «absolutism» and «mercantilism».

Keywords: Military revolution; dynastic state; confessional state; parliament; English Civil War; Charles I of England; Oliver Cromwell.

... The people in general were so ignorant of their duty, as that not one perhaps of ten thousand knew what right any man had to command him, or what necessity there was of King or Commonwealth, for which he was to part with his money against his will; but thought himself to be so much master of whatsoever he possessed, that it could not be taken from him upon any pretence of common safety without his own consent. King, they thought, was but a title of the highest honour... and he was thought wisest and fittest to be chosen for a Parliament that was most averse to the granting of subsidies or other public payments.

Thomas Hobbes, Behemoth, (1681)

La historia de Inglaterra sigue siendo conceptualizada como un modelo de exceptionalism, pero sería un serio error pensar que no hubo trasformaciones profundas dentro del seno de la economía política del país durante el siglo de oro ${ }^{1}$. La idea es que la trayectoria del estado inglés fue tan única que resulta difícil, sino imposible, situarlo dentro de un marco histórico o compararlo con otros gobiernos y regímenes. Pero, de la misma forma, parece claro que no hubo un modelo inglés: mejor dicho,

1. La cita de Hobbes procede de BRADDICK, M.: «State formation and social change in early modern England: a problem stated and solutions suggested», Social History, 16/1, 1991, pp. 1-17, p. 9.

Ediciones Universidad de Salamanca / అ@@ Stud. his., H. ${ }^{a}$ mod., 41, n. 1 (2019), pp. 231-258 
ya parece evidente que el gobierno de Londres, y su organización política, financiera y militar, se transformó a lo largo del siglo XVII. El gobierno de Elizabeth I (15581603) dispuso de ingresos muy limitados, y el desembolso en la armada durante la famosa guerra contra Felipe II de España fue sorprendentemente pequeño. Es más, en muchas de los conflictos de los reyes Stuart, Inglaterra, su flota y navegantes, fueron más víctimas que verdugos. De esta forma, las pérdidas sufridas por los corsarios de Dunkerke, Salé, Argel y aun Waterford y Wexford (en Irlanda) fueron significativas y - quizá - tan traumáticas que dejaron una huella en la memoria colectiva del país. De hecho, muchas operaciones navales del Seiscientos $(1625,1627,1628$, $1640,1652-1653,1656-1657,1666-1667,1672-1673)$ llevaron al gobierno a un crisis inmediata y profunda. Y cómo no, se ha situado el origen fundamental de los fracasos navales en las finanzas reales. Pero - aquí hay la contradicción - al mismo tiempo, la cultura política se ha enfocado en el temor al gobierno arbitrario en Londres, algo que se manifestó en recelos en el momento de contribuir con impuestos sin fines definidos y específicos. Por esta razón, la historia de Gran Bretaña está caracterizada por una dialéctica entre los conceptos de un estado confesional, con una ideología calvinista, una retórica mesiánica y ambiciones imperiales, y como contrapeso, un gobierno dominado por una constitución medieval, un concepto de naturaleza y equilibrios y una fe - a su vez, ciega - en las milicias como defensoras del reino ${ }^{2}$. Incluso, los embajadores de Carlos II (1665-1700) en Londres en la década de 1690 eran conscientes de la profunda contradicción en la política de este país, para ellos tan extraño y con una forma de gobernar tan irregular ${ }^{3}$.

2. YATES, F. A.: Astrea: The Imperial Theme in the Sixteenth Century. Londres, 1975; para las operaciones y finanzas de Elizabeth, WERNHAM, R. B.: «Amphibious Operations and the Elizabethan Assault on Spain's Atlantic Economy», en TRIM, D. J. B. y FISSEL, M. C. (eds.): Amphibious Warfare 1000-1700. Commerce, State Formation and European Expansion. Leiden, 2006, pp.181-215; observaciones muy generales sobre Inglaterra, HALE, J.R.: War and Society in Renaissance Europe 1450-1620. $2^{a}$ edición, Stroud, 1998, pp. 28-29, 33-34. THOMAS, K.: The Ends of Life. Roads to Fulfilment in Early Modern England. Oxford y Nueva York, 2009 , p.65. En cuanto a las milicias, una comparación con el contexto continental sería interesante y desvelaría unas similitudes - un contrapeso al modelo del exceptionalism. Por ejemplo, PARDO MOLERO, J. F.: La defensa del imperio. Carlos V, Valencia y el Mediterráneo, Madrid, 2000; FLORISTÁN IMÍZCOZ, A.: «Neoforalimso, nuevos fueros y conquistas. Navarra en la Monarquía de Carlos II», en GARCÍA GARCÍA, B. J. y ÁLVAREZ-OSSORIO ALVARIÑO, A. (eds.): Visperas de Sucesión. Europa y la Monarquía de Carlos II. Madrid, 2015, pp.81-107; y RUIZ IBAÑEZ, J. J. (ed.): Las milicias del rey de España. Sociedad, politica e identidad en las Monarquías Ibéricas, Madrid, 2009.

3. WILLIAMS, P.: «'A Kingdom of such instability and of such a strange form of government'. Irish privateers, Spanish ambassadors and the perception of England and the English, 1688-1697», en GARCÍA HERNÁN, E. y LARIO DE OÑATE, M.C. (eds.): La presencia irlandesa durante las Cortes de Cádiz en España y América, 1812. Política, Religión y Guerra. Valencia, 2013, pp. 363-381, pp. 365-66, 372-76.

Ediciones Universidad de Salamanca / @®@@ Stud. his., H. ${ }^{a}$ mod., 41, n. 1 (2019), pp. 231-258 
En cuanto a la hegemonía continental, hay que subrayar que las capacidades del estado bajo Charles I fueron profundamente diferentes a las del gobierno de los Hannover, George I (1714-1727) y sus sucesores. Para muchos historiadores británicos, el origen de los éxitos militares de Gran Bretaña en la época de los Luces fue precisamente la existencia de un estado pequeño y poco desarrollado bajo James I (1603-1625), Charles I y, con matices, Cromwell y Charles II (1660-1685). Francia, Castilla, Nápoles, los Países Bajos y otros estados continentales no tuvieron esa suerte. Existe todo un debate sobre cuándo Inglaterra dio el paso decisivo hacia el estado capaz de buscar la guerra que vemos en el siglo XVIII: unos historiadores (J. S. Wheeler, B. Capp, M. Duffy, S. R. Hornstein) proponen que las décadas de 1640 y 1650 fueron claves, siendo en esos momentos cuando la política de Charles I (1625-1649) y la guerra civil dieron como resultado una nueva forma o diseño del ejército y de la armada; otros especialistas constatan que el paso decisivo fue después de la «Revolución Gloriosa» (1688) y durante la Guerra de los Nueve Años (1688$1697)^{4}$. Tales transformaciones también se han constatado desde el punto de vista financiero. Se ha calculado que entre las décadas de 1590 y 1670, los ingresos del gobierno en Norfolk crecieron por un factor de 16 (es decir, aumentaron un 1.600 por ciento en esa provincia) $)^{5}$. Un historiador ha sugerido que la famosa «revolución financiera» se inauguró en la década de 1660, gracias a la efectividad de los nuevos tributos (el Royal Aid y Further Supply) 6 .

La historia de Inglaterra durante siglo XVII ha sido expuesta, en las últimas décadas, a un profundo proceso de revisionismo que ha transformado la comprensión del gobierno, el Parlamento, la religión, la corte y la cultura. En el marco de este monográfico, enfocado en la hegemonía continental, no es posible tratar todas las interpretaciones, solo las que sirven para poner en relieve la organización militar y explicar las crisis consecutivas de esta época. No es la ocasión para llevar a cabo un análisis de los lazos diplomáticos, ni una explicación de los acontecimientos militares y navales que, por otra parte, ya han sido estudiados en las obras de eminentes historiadores como Porfirio Sanz, Igor Pérez Tostado, Óscar Ruiz Fernández,

4. WHEELER, J. S.: The Making of a World Power. War and the Military Revolution in Seventeenth Century England. Stroud, 1999, pp. $38 \mathrm{ff}$ y capítulo 3 «The Naval Revolution». Se nota la discusión sobre el debate de la «military revolution», con John Brewer y Richard Harding, pp. 52 y siguientes; CAPP, B.: Cromwell's Navy. The Fleet and the English Revolution. Oxford 1989; DUFFY, M. (ed.): The military revolution and the state 1500-1800. Exeter, 1980; HORNSTEIN, S. R.: The Restoration Navy and English foreign trade, 1674-1688. Aldershot 1991; BRADDICK, M. J.: «An English Military Revolution?», The Historical Journal, 36/4, 1993, pp.965-975; sobre la «financial revolution», DICKSON, P. G. M.: The Financial Revolution in England: A Study in the Development of Public Credit, 1688-1756. Londres, 1967; BREWER, J.: The Sinews of Power. War, Money and the English State 1688-1783. Nueva York, 1989.

5. BRADDICK, M.: «State formation and social change in early modern England: a problem stated and solutions suggested», Social History, 16/1,1991, pp. 1-17, p. 2.

6. ROSEVEARE, H.: The financial revolution 1660-1760. Londres, 1991. 
PHILLIP WILLIAMS

¿UN PUEBLO IGNORANTE DE SU DEBER? EL 'ESTADO CONFESIONAL' DE INGLATERRA

Y LAS LIMITACIONES ESTRATÉGICAS EN LA ÉPOCA DE CHARLES I Y OLIVER CROMWELL

Carmen María Fernández Nadal, N. A. M. Rodger y Ángel Alloza Aparicio7. Este artículo pretende plantear algunas ideas interesantes sobre el estado inglés, las interpretaciones recientes en cuanto a los orígenes de las guerras civiles (1642-1646 y 1648), el marco interpretativo general y las obras de los historiadores señalados, con la esperanza de que puedan servir para contextualizar el debate en torno a las relaciones entre Felipe IV de España (1621-1665) y Charles I de Inglaterra y Oliver Cromwell (1599-1658).

Hay dos interpretaciones globales sobre el desarrollo de los estados europeos en el siglo XVII. La primera es que durante la época moderna se vio en el viejo continente la construcción de un estado moderno, con el nacimiento de un amplio sistema administrativo y los mecanismos financieros adecuados para sostener las ambiciones de los distintos príncipes - o, al menos, de los más importantes. Esta interpretación (de state formation) encaja bien con los modelos del «absolutismo» y de una «revolución militar», es decir, un proceso de centralización de la autoridad política y del poder militar en manos del príncipe y su consecuente dominación política de la nobleza y otras élites ${ }^{8}$.

7. ALLOZA APARICIO, Á.: Diplomacia caníbal. España y Gran Bretaña en la pugna por el dominio del mundo, 1638-1660. Madrid, 2015; SANZ CAMAÑES, P.: Los ecos de la Armada. España, Inglaterra y la estabilidad del Norte. Madrid, 2013; PÉREZ TOSTADO, I.: Anglo-Spanish Relations During the English Civil Wars. Londres (en prensa); RUIZ FERNÁNDEZ, O.: England and Spain in the Early Modern Era. Londres (en prensa); RODGER, N. A. M.: The Safeguard of the Sea. A Naval History of Britain. Volume One 660-1649. Londres, 1997; RODGER, N. A. M.: The Command of the Oceans. A Naval History of Britain, 16491815. Londres, 2004; RECIO MORALES, O.: España y la pérdida de Ulster: Irlanda en la estrategia politica de la Monarquía hispánica, (1602-1649). Madrid, 2003; RECIO MORALES, O.: Ireland and the Spanish Empire, 1600-1825. Dublín, 2010; FERNÁNDEZ NADAL, C. M., La política exterior de la monarquía de Carlos II. El Consejo de Estado y la Embajada en Londres (1665-1700). Gijón, 2008.

8. Evidentemente, la historiografía sobre el absolutismo es enorme: una búsqueda en Dialnet por la palabra «absolutismo» arroja nada menos que 705 páginas de estudios académicos. Se puede empezar con HENSHALL, N.: The Myth of Absolutism: Change and Continuity in Early Modern European Monarchy. Londres, 1992; JAMES, A.: The Origins of French Absolutism, 1598-1661. Londres, 2006; MOUSNIER, R.: The Institutions of France under the Absolute Monarchy. Chicago, 1979; DUCCHARDT, H., y ASCH, R.G. (eds.): El absolutismo (1550-1700), ¿un mito?: revisión de un concepto historiográfico clave. Madrid, 2000; quizá su formulación más conocida sea la visión marxista de ANDERSON, P.: Lineages of the Absolutist State. Londres, 1974; la dimensión intelectual se explora en CUTTICA, C. y BURNESS, G. (eds.): Monarchism and Absolutism in Early Modern Europe. Londres, 2012. A este respecto, merece la pena recordar la tesis de Michael Roberts, que proponía que la revolución militar de la época moderna ("una de las trasformaciones más decisivas en la bistoria bumana») desembocaría en las dictaduras del siglo XX. De esta forma, un elemento clave en muchos de los argumentos del absolutismo ha sido que la evolución del nuevo estado militar de la época de Carlos V o Francisco I llevaría a los regímenes de Hitler, Stalin y las dictaduras en Italia, España y Portugal. ROBERTS, M.: «The Military Revolution, 1560-1660», en RODGERS,

Ediciones Universidad de Salamanca / అ@@ Stud. his., H. ${ }^{a}$ mod., 41, n. 1 (2019), pp. 231-258 
PHILLIP WILLIAMS

¿UN PUEBLO IGNORANTE DE SU DEBER? EL 'ESTADO CONFESIONAL' DE INGLATERRA

Y LAS LIMITACIONES ESTRATÉGICAS EN LA ÉPOCA DE CHARLES I Y OLIVER CROMWELL

La otra interpretación, mucho más influyente en el mundo anglosajón, pero posiblemente - menos conocida en el ámbito intelectual continental, es que, lejos de un momento de centralización y dominación, el siglo XVII vio el despliegue de un estado que dependía de una serie de mecanismos de financiación que, por ser muy distintos, estaban todos destinados a fracasar antes o después?. La única cuestión fue el momento del desplome, ya que el desequilibrio entre las exigencias de la guerra, la riqueza y recursos de la sociedad y las capacidades de recaudación del estado era extremo. Esta línea de pensamiento destaca que los beneficiados por los cambios del grand siècle no fueron exclusivamente los príncipes (el estado) sino también las élites que se hicieron cargo de los sistemas financieros y administrativos en los momentos de crisis - los numerosos momentos de crisis. Esta línea de pensamiento rechaza implícitamente la teoría de modernización a través de state formation o nation building. $\mathrm{Al}$ contrario, los estados del ancien régime eran construcciones irregulares e incapaces de sostener el peso de la guerra; correspondieron más a un mecanismo para pacificar las élites que para efectuar conquistas en territorios

C. J. (ed.): The Military Revolution Debate. Readings on the Military Transformation of Early Modern Europe. Boulder Colorado, 1995, pp.13-36; PARKER, G.: The Military Revolution. Military innovation and the rise of the West, 1500-1800. Cambridge, 1988; BLACK, J.: A military revolution? Military change and European society 1550-1800. Londres, 1991; una interpretación reciente de la revolución militar irlandesa se encuentra en De MESA, E.: The Irish in the Spanish Armies in the Seventeenth Century. Woodbridge, 2014; en la misma línea, NIEVAS, F.: «La forma de guerra en el absolutismo», Cuadernos de Marte, 0, 2010, pp. 9-32; aunque presenten una visión bastante tradicional, las obras de J. R. Hale todavía resultan muy útiles, HALE, J. R.: War and Society..., passim, esp. pp. 24-25 y capítulo 2; HALE, J. R.: The Civilisation of Europe in the Renaissance. Londres, 1993.

9. Véase, por ejemplo, PARROTT, D.: Richelieu's Army. War, Government and Society in France, 1624-1642. Cambridge, 2001; PARROTT, D.: «France's War against the Habsburgs, 1624-1659: the Politics of Military Failure», en MAFFI, D. y GARCÍA HERNÁN, E. (eds.): Guerra y Sociedad en la monarquía hispánica: política, estrategia y cultura en la Europa moderna (1500-1700). 2 vols., Madrid, 2006, vol. I, pp. 31-48; ROWLANDS, G.: The Dynastic State and Army under Louis XIV. Royal Service and Private Interest, 1661 to 1701. Cambridge, 2002; la incorporación de nuevos estados y territorios se estudia en GREENGRASS, M. (ed.): Conquest and Coalescence. The Shaping of the State in Early Modern Europe. Londres, 1991. La eficacia e integridad militar de Francia (el concepto de «strategic heartlands») se examina en ROWLANDS, G.: «Moving Mars: the Logistical Geography of Louis XIV's France», French History, 25, 2011, pp. 492-514; otro estudio sobresaliente sobre el medio ambiente, sistemas logísticos y la guerra es WHITE, L.: «Strategic Geography and the Spanish Habsburg Monarchy's Failure to Recover Portugal, 1640-1668», The Journal of Military History, 71/2, 2007, pp. 373-409: ambos estudios tratan de cuestionar el concepto básico de una revolución militar, tal y como la presentaron Roberts y Parker; ponen énfasis sobre consideraciones operacionales. La obra maestra en contra del concepto de una transformación en la profesión de armas es, por supuesto, PARROTT, D.: The Business of War: Military Enterprise and Military Revolution in Early Modern Europe. Cambridge, 2012.

Ediciones Universidad de Salamanca / @®@@ Stud. his., H. ${ }^{a}$ mod., 41, n. 1 (2019), pp. 231-258 
extranjeros o dominar la sociedad doméstica. El tema de la corrupción es, en este paradigma, una question mal posée: el propósito del estado del renacimiento fue sostener la nobleza, las ciudades, las élites sociales e institucionales, no someterlas a la corona ${ }^{10}$.

Un modelo parecido se ha aplicado al estado inglés en el siglo XVII, que Michael Braddick analiza como un «estado parcialmente diferenciado», en el cual sus oficiales eran, casi siempre, miembros de la clase gobernante y representantes de la sociedad local ${ }^{11}$. Lo que tiene lugar en Inglaterra a lo largo del Seiscientos no es la creación de un estado a través de una clase de oficiales reales sin ninguna vinculación con la sociedad provincial; todo lo contrario, el gobierno central seguía dependiendo de las élites regionales, muy pendientes de la prioridad social de ser un buen vecino (neighbourliness) y de respetar las normas en su pueblo o «county». Paradójicamente, el crecimiento en las cantidades recaudadas por el treasury se logró actuando a través de la nobleza menor (gentry), no por encima de ella ${ }^{12}$. En este paradigma, lo importante en el incremento de la recaudación fiscal no fue la cantidad que se pidiera a la provincia, sino la forma en que Londres presentaba su demanda para dineros y servicios, la «form of mediation». Como ha señalado Ian W. Archer, el incremento de los ingresos dedicados a las milicias de Londres en el siglo XVI se efectuó a través de un nuevo acuerdo entre el gobierno y las élites que colocó una mayor parte del peso sobre las clases inferiores: eso fue una fiscalidad regresiva en cuanto a sus consecuencias y forma ${ }^{13}$. Lo decisivo fue el común interés de ambas partes, corona y clase gobernante, en mantener su posición frente a los otros rangos de la sociedad y los desafíos del grand siècle (guerra, rebelión, hambre, disturbios populares y la inmoralidad) ${ }^{14}$.

10. Una interpretación marxista se presenta en BEIK, W.: Absolutism and Society in Seventeenth-Century France. State Power and Provincial Aristocracy in Languedoc. Cambridge 1985; una línea más conservadora (aunque no tan distinta, al fin y al cabo), ROWLANDS, The Dynastic State... Los estudios de Beik y Rowlands presentan un amplio panorama historiográfico y teórico en sus introducciones. Véase también COLLINS, J.: Classes, Estates and Order in Early Modern Brittany. Cambridge, 1994 y The State in Early Modern France. Cambridge et al, 1995; MACKAY, R.: The Limits of Royal Authority. Resistance and Obedience in SeventeenthCentury Castile. Cambridge, 2007.

11. BRADDICK, M.: «The Early Modern English State and the Question of Differentiation, from 1550 to 1700", Comparative Studies in Society and History, 38/1, 1996, pp. 92-111.

12. "The increase in effectiveness rested on the co-operation of county and village elites, not on central expansion.» BRADDICK, M.: «State formation and social change in early modern England», pp. 3, 6, 8 .

13. ARCHER, I.W.: «The Burden of Taxation on Sixteenth-Century London», The Historical Journal, 44/3, 2000, pp. 599-627.

14. Kevin Sharpe también concluye en que no fueron las cantidades de impuestos las que causaron problemas en la década de 1630 , sino la forma de recaudar el dinero, la retórica y la justificación para tales impuestos - la forma de «mediation»; dicho eso, pone énfasis en que

Ediciones Universidad de Salamanca / @®@@ Stud. his., H. ${ }^{a}$ mod., 41, n. 1 (2019), pp. 231-258 
Desde 1975, las líneas dominantes de investigación han rechazado las tradiciones Whig y Marxista, ya que es cada vez más difícil encuadrar los disturbios políticos y las guerras civiles como las consecuencias de causas estructurales, como algo natural e inevitable cuando un programa de absolutismo continental (manifestado en Charles I y su esposa francesa, Henriette Marie) chocó con las libertades y actitudes políticas de Inglaterra. También se ha rechazado la idea de que había un grupo o partido formado, dentro o fuera de la Casa de los Comunes (House of Commons), en clara oposición a la corona. Historiadores como Conrad Russell, Kevin Sharpe y John S. Morrill intentaron demostrar que el conflicto que estalló en 1642 no tuvo sus orígenes en dos ideologías políticas, ni en movimientos sociales, culturales o confesionales que buscaran un cambio profundo en la organización del país. En su forma más sencilla, la idea de los revisionists es que fue Charles I, antes que la sociedad, la cultura protestante o un partido parlamentario dentro del sistema político, la causa de las dos guerras civiles. El monarca era el gran innovador, sobre todo en cuanto a su política confesiona ${ }^{15}$. Había un clima político dominado por facciones, no por partidos ideológicos ${ }^{16}$.

El primer paso en esta nueva interpretación fueron las finanzas reales. Según un cálculo de Patrick O’Brien y Philip Hunt, el aparato gubernamental solo era capaz de embolsar un $4 \%$ de los ingresos nacionales en el siglo XVI ${ }^{17}$. Impuestos sobre los señoríos, fincas y bienes fueron registrados muy por debajo del valor real de esos «lands and goods»: la evaluación de la riqueza de un jefe de familia nunca sobrepasó un 10 por ciento de sus posesiones, e incluso solo llegó al 3 por ciento

las cantidades de dinero recaudadas en 1640 y 1641 y durante la guerra civil estaban muy por encima de las del «personal rule» de 1629-1640. SHARPE, K.: The Personal Rule of Charles I. Nueva Haven y Londres, 1992, pp. 926 y siguientes.

15. Véase el estudio en el "Dictionary of National Biography» de Charles I escrito por MORRILL, J. S. y KISHLANSKY, M. A. disponible en: https://doi.org/10.1093/ref:odnb/5143. RUSSELL, Origins of the English Civil War, p. 1 describe «... an accidental war, growing out of the panic and confusion which followed the failure of the Parliamentary leaders' plans for a bloodless coup...» En sus obras posteriores, echa más culpa sobre el rey que sobre los accidentes.

16. John Pym, por ejemplo, ya no se encuadra sencillamente como un defensor de los derechos del Parlamento. Todo lo contrario, se destaca que estaba negociando con los escoceses en 1640 (en efecto, un acto de traición) y estaba en comunicación con el rey para reemplazar al conde de Strafford (Thomas Wentworth, el Earl of Strafford, 1593-1641) como ministro real, en 1641. Lejos de ser un hombre con una política definida - en la visión Whig, era el gran héroe de Parlamento y la ley - ya se le considera como un socio de una facción encabezada por Francis Russell, IV conde de Bedford y otros nobles. KISHLANSKY, M.: A Monarchy Transformed. Britain 1603-1714. Londres, 1996, pp. 142-45. Por esta razón, Pym y sus colaboradores forman parte de la tesis de John Adamson, que propone una conspiración de grandes contra el monarca, como se verá más adelante.

17. O'BRIEN, P. K. y HUNT, P. A., «The rise of a fiscal state in England, 1485-1815», Historical Research, 66/160, 1993, pp. 129-176, pp.154, 159.

Ediciones Universidad de Salamanca / @®@@ Stud. his., H. ${ }^{a}$ mod., 41, n. 1 (2019), pp. 231-258 
(según quejas contemporáneas) ${ }^{18}$. El problema central se encontraba en la naturaleza del gobierno, puesto que Londres dependía de agentes locales para evaluar las rentas y posesiones de los nobles, mercantes y «gentry» de Bristol, Cheshire o Cornwall -al mismo tiempo, sus agentes y oficiales eran precisamente los nobles, mercantes y gentry de Bristol, Cheshire o Cornwall. Elisabeth I pudo presentarse como una nueva Jezabel, una reina protestante, pero sus recursos financieros y militares estaban muy por debajo de los disponibles por Henri IV de Francia (1589-1610) o Felipe III de España (1598-1621). El presupuesto dedicado a la armada en 1564 - el año antes del asedio de Malta - fue nada más que de $£ 6.000$. Aun en los años de guerra (1585-1603) solo llegaría a unos £87.00019. Después de la Gran Armada de 1588 la corona inglesa tuvo que afrontar una situación financiera altamente complicada. Su solución fue vender muchos de sus estates, los señoríos y las fincas del patrimonio real. De hecho, en las décadas posteriores a 1588 se embolsaron más de dos millones de libras por este método 20 .

Para el profesor Russell, el Parlamento no fue una institución decisiva, ni mucho menos. La mayoría de los acontecimientos políticos tuvieron lugar fuera del palacio de Westminster. La asamblea se presentaba, esencialmente, como «reuniones ad hoc que correspondieron a la necesidad de responder a acontecimientos en otros lugares». $\mathrm{El}$ «consejo Privy» (Privy Council) y la Corte eran los escenarios donde se discutieron las grandes decisiones - en otras palabras, eran las verdaderas sedes de poder. Es más, no había, en ningún sentido, dos partidos en la asamblea antes de 1629. Lejos de ser un teatro de conflicto protagonizado por grupos rivales, los parlamentos de James I se interpretan hoy en día como escenarios de concordia y cooperación -o, mejor dicho, escenarios en los cuales la concordia y cooperación eran tan importantes como las polémicas y quejas. Es verdad que la situación cambió mucho en los primeros años del reinado de Charles I, que estuvieron marcados por una serie de crisis consecutivas. Pero los revisionists insisten en que estos momentos de alta tensión fueron causados por las políticas del mismo rey y su favorito, el duque de Buckingham. Sobre todo, sus decisiones de declarar la guerra a Felipe IV (en 1625) y Louis XIII (en 1627) le llevaron a unas polémicas reuniones del Parlamento, con recriminaciones violentas contra los consejeros del rey y unas maniobras de facciones que concluyeron en la asamblea de 1629, cuando dos diputados (Denzil Holles y Benjamin Valentine) pusieron sus manos sobre el jefe (el Speaker of the House) para mantenerle en su silla mientras que Sir John Eliot leía su queja contra la política real.

18. SHARPE, The Personal Rule of Charles I..., p. 9 (sobre las finanzas reales, véase pp. 9-23).

19. WHEELER, Making of a World Power..., p. 22 y ss.

20. CARLTON, C.: Charles I. The Personal Monarch. $2^{\mathrm{a}}$ ed., Londres y Nueva York, 1995, pp. 192-93; SMITH, Emergence..., pp. 254 y ss.; HOYLE, R. W. (ed.), The Estates of the English Crown, 1558-1640. Cambridge, 1992.

Ediciones Universidad de Salamanca / 요 Stud. his., H. ${ }^{a}$ mod., 41, n. 1 (2019), pp. 231-258 
Para Russell, a lo largo de las primeras décadas del siglo el problema fue que los diputados del Parlamento no entendieron la profundidad de la crisis de las finanzas reales, algo que llevó a los reyes a menospreciar la asamblea y verla como una institución vieja y obstruccionista, si no inútil y arcaica ${ }^{21}$. Después del asesinato del duque de Buckingham en Portsmouth, en 1628, y la tormentosa convocatoria del Parlamento, en 1629, Charles I decidió gobernar sin la asamblea representativa, utilizando los impuestos feudales para solucionar las serias deficiencias en las milicias y establecer la armada como una fuerza profesional y permanente. Para Russell, Sharpe y muchos revisionists, esa política no conllevó grandes quejas. «En 1637 Inglaterra era, escribe el profesor Russell en unas páginas celebradas por su iconoclasia, un país en calma y no estaba al borde de una revolución... Hay muy pocas pruebas de que bubiera una parte significativa de súbditos del rey interesados en instigar una revolución de haber sido posible» ${ }^{22}$.

Eso sí, la falta de dinero siguió siendo un problema muy serio. Los escasos recursos financieros de la corona influyeron tanto en la política doméstica (la política confesional, el mantenimiento del orden y la moralidad) como en la estrategia exterior. A lo largo de la década de 1630, Charles I pensaba en recurrir a una alianza con Felipe IV, quien buscaba una forma de conseguir el paso de sus navíos desde Galicia y Guipúzcoa a los Países Bajos meridionales. Estos intentos se concretaron en 1639, con una alianza formal: desafortunadamente, el acuerdo tuvo consecuencias nefastas para ambas partes, siendo el origen de la Batalla de las Dunas (the Battle of the Downs, un desastre para Felipe IV) y una de las causas principales de las sospechas contra el rey sobre sus lazos con poderes católicos (un asunto cada vez más serio para Charles I y sus críticos) ${ }^{23}$. Sin duda, el tesoro iba embolsando cada vez mayores cantidades de impuestos, sobre todo después del inicio de la guerra civil en 1642. En una obra conocida, James Scott Wheeler propone que hubo una revolución militar a

21. RUSSELL, C.: Parliaments and English Politics 1621-1629. Oxford, 1979, p. 1; se cita otra frase célebre de Russell: «Las dificultades de los primeros Stuart no eran dificultades con sus Parlamentos; sino dificultades que se reflejaron en sus Parlamentos.», p. 417; RUSSELL, C.: «Parliament and the king's finances», en RUSSELL, C. (ed.): The Origins of the English Civil War. Londres, 1973, pp. 91-116; para Russell, los conflictos sobre impositions o aduanas establecidas sin consultar al Parlamento constituyeron la única verdadera crisis constitucional del reinado de James I; estas interpretaciones ya son mayoritarias, véase el análisis de MORRILL, y KISHLANSHY, «Charles I...», pp. 12-17.

22. RUSSELL, C.: The Fall of the British Monarchies 1637-1642. Oxford, 1991, pp. 1-2. Para Morrill, hubo quejas contra el rey en Cheshire, pero al fin se implementó una buena parte del programa del gobierno, MORRILL, J. S.: Cheshire 1630-1660: County Government and Society during the English Revolution. Oxford, 1974, p. 22.

23. SHARPE, The Personal Rule of Charles I..., pp. 70-75, 548-49, 909 y siguientes, 939-40; MORRILL, y KISHLANSHY, «Charles I... », p. 31; ALLOZA APARICIO, Diplomacia Canibal..., pp. 29-43. 
mediados del siglo XVII; puede que su argumento sea demasiado optimista en cuanto a los cambios militares en Gran Bretaña durante las guerras civiles y el régimen de Oliver Cromwell. Se nota, por ejemplo, que ignora los resultados de las guerras de esta época ${ }^{24}$. Su énfasis sobre el incremento de los ingresos del gobierno no toma en cuenta el enorme aumento en los costes de navíos (cada vez más sofisticados en cuanto a su construcción), cañones, pólvora y tripulaciones ${ }^{25}$.

Esta circunstancia, sin duda, siguió siendo un elemento clave en la historia política. En diciembre de 1653, Oliver Cromwell clausuró el Rump Parliament (lo que quedaba de los diputados elegidos en 1640), haciéndose caudillo o «Lord Protector». Este cambio político fue necesario para superar las tensiones entre el agujero financiero y la situación de la armada y del treasury. Por fin, en 1654, Londres tuvo que buscar la paz con Ámsterdam (conclusión de la primera guerra holandesa, the First Dutch War, 1652-1654) a causa de la crisis en las finanzas ${ }^{26}$. Se puede comprobar la fragilidad relativa del estatus financiero-militar de Londres en la década de 1660 con la venta de Dunkerque a Louis XIV. Sencillamente Charles II no disponía de los recursos necesarios para mantener esta plaza estratégica. Tánger, en Marruecos, fue otra oportunidad perdida (adquirida en 1662 como parte de la dote de Caterina de Braganza; abandonada en 1684) ${ }^{27}$. La segunda (1665-1667) y tercera guerra (1672-1674) con Holanda (The Second Dutch War and Third Dutch War) fueron, sin muchos matices, desastres para Londres ${ }^{28}$. En ambos casos, el gobierno tuvo recursos para movilizar la armada durante unos meses: por supuesto, los problemas llegaron cuando, el tesoro ya vaciado, Londres tuvo que resistir una armada holandesa que sí que recurría a un sistema eficaz de finanzas. En junio de 1667, una buena parte de la armada y del astillero real de Londres fueron quemados por los soldados holandeses ('the Burning of the Medway', en Chatham y Gillingham). En noviembre de 1673, el Parlamento votó para negar a Charles II un presupuesto para continuar la guerra. Este hecho, y la coyuntura político-confesional doméstica, forzó al rey a abandonar la guerra en un contexto no menos humillante que el de 1668.

En este contexto, merece la pena subrayar que a lo largo del Seiscientos la armada inglesa fue un fracaso, o, mejor dicho, que hubo múltiples fracasos (las campañas catastróficas de 1625, 1627 y 1628; las tres guerras contra los holandeses; aun 1688

24. WHEELER, Making of a World Power. Para comparación, WERNHAM, «Amphibious Operations...».

25. Los navíos de guerra eran «the single most costly, powerful and technologically advanced weapon systems of the period», BLACK, J.: The British seaborne empire, Nueva Haven, 2004, p. 30.

26. RODGER, Command of the Oceans..., pp.18-19.

27. Ibid., 65-66; KISHLANSKY, A Monarchy Transformed..., pp. 230-31, 236-37; WHEELER, Making of a World Power..., pp. 88-89.

28. RODGER, Command of the Oceans..., capítulos 5 y 6 . 
se puede interpretar como un fracaso, aunque otra visión plantea una «conspiración naranja» contra el último rey católico, James II, de parte de sus propios oficiales y almirantes) y que los triunfos fueron pocos ${ }^{29}$. En muchos aspectos, la historia de la armada inglesa encuadra perfectamente en la contradicción entre los recursos del estado y el programa de legitimación: el desembolso en administrar las fuerzas navales y desplegarlas en expediciones contra los enemigos fue tan grande que conllevó múltiples problemas políticos para los reyes Stuart y para Cromwell ${ }^{30}$. Campañas que se habían iniciado con la esperanza de embolsar dineros por conquistas, corso y comercio, acabaron vaciando la bolsa del rey y empeorando la situación política de la corona y del Lord Protector. Es más, los éxitos conseguidos bajo Cromwell y el almirante Robert Blake (1598-1657) - la conquista de Jamaica; la captura de parte de las flotas de Indias en 1656 y 1657 - no compensaron los gastos. Como ha confirmado el profesor Alloza en su estudio reciente, cuando Felipe IV decidió confiscar los bienes de las redes inglesas en Sevilla, la pérdida para sus mercaderes fue, con toda probabilidad, mayor que las ganancias de la piratería en 1656 y 1657. Hay también que destacar que tales acciones interrumpieron redes comerciales que unían Sevilla y Londres, La Coruña y Bristol ${ }^{31}$.

Se puede proponer, como contexto más generalizado, que las capacidades recaudatorias del estado no eran iguales a los desembolsos, la piratería era una vía de ingresos muy irregular y las movilizaciones navales eran cada vez más costosas ${ }^{32}$.

29. RODGER, The Safeguard of the Sea..., pp. 347-363; RODGER, Command of the Oceans..., pp.136-40; KENNEDY, P.: The Rise and Fall of British Naval Mastery. Londres, 2001; LAVERY, B.: Empire of the Seas. The Remarkable Story of How the Navy Forged the Modern World. Londres, 2012, capítulos 3 y 5.

30. Una interpretación más matizada sobre la capacidad guerrera del estado inglés en el siglo XVI y bajo los primeros reyes Stuart se presenta en las excelentes obras de Mark Charles Fissell. Pone énfasis sobre las campañas en Irlanda. Véase, por ejemplo, «English Amphibious Warfare, 1587-1656: Galleons, Galleys, Longboats and Cots», en TRIM y FISSEL, Amphibious Wafare..., pp. 217-261.

31. ALlOZA APARICIO, Diplomacia Caníbal..., capítulo 6.

32. Sobre los desembolsos realizados para las operaciones en 1665-1667 y las consecuencias políticas, RODGER, Command of the Oceans..., pp. 77-79. Los holandeses gastaron (£11 millones) más del doble que los británicos, p. 79; «Para Charles II la guerra [de 1672-1674] había sido un desastre político» y económico, pp. 85-86. Sobre las limitaciones del uso de la piratería como instrumento de guerra, véase el estudio de MURPHY, E.: Ireland and the War at Sea, 1641-1653. Londres, 2012, capítulo 3. Unas perspectivas interesantes se encuentran en: STARKEY, D. J. y MCCARTHY, M.: «A Persistent Phenomenon: Private Prize-Taking in the British Atlantic World c.1540-1856», en AMIRELL, S. E. y MÜLLER, L. (eds.): Persistent Piracy. Maritime Violence and State-Formation in Global Historical Perspective. Basingstoke y Nueva York, 2014, pp. 131-151; ANDREWS, K. A.: Ships, money and politics. Seafaring and naval enterprise in the reign of Charles I. Cambridge, 1991; algunos estudios han destacado las relaciones entre el comercio y el corso y subrayado que la violencia era una opción menor, el arma de los fracasados: OTERO LANA, E.: Los corsarios españoles durante la decadencia

Ediciones Universidad de Salamanca / @®@@ Stud. his., H. ${ }^{a}$ mod., 41, n. 1 (2019), pp. 231-258 
PHILLIP WILLIAMS

¿UN PUEBLO IGNORANTE DE SU DEBER? EL 'ESTADO CONFESIONAL' DE INGLATERRA

Y LAS LIMITACIONES ESTRATÉGICAS EN LA ÉPOCA DE CHARLES I Y OLIVER CROMWELL

Puede ser, como ha planteado don Hugo O’Donnell, que las defensas de las Indias eran bastante eficaces durante la época moderna ${ }^{33}$. Además, como ha señalado $\mathrm{N}$. A. M. Rodger, existían grandes limitaciones en cuanto al uso del poderío naval, en el sentido de que Londres tuvo que decidir entre piratear contra los convoyes holandeses y proteger los propios navíos y comercio; otra decisión, más estratégica, fue entre mantener una armada, bien como mecanismo para proseguir guerras contra París, Madrid y Ámsterdam o, precisamente, para proteger los convoyes y cazar los barcos de Argel, Túnez, Salé, Guipúzcoa y Dunkerque ${ }^{34}$.

La imagen de Inglaterra como víctima de otros poderes y sus flotas, incapaz de mantener una armada y expuesta a riesgos y, a su vez, humillaciones, encuadra bien con el argumento de que los orígenes de los problemas de Charles I no fueron exclusivamente domésticos. Un grupo de importantes historiadores - David Hebb, Linda Colley, Kenneth R. Andrews, Nabil Matar y el profesor Braddick - reconocen que una de las dificultades clave para Charles I fue precisamente la piratería berberisca, una amenaza a las costas y comercio que hacía imprescindible una armada ${ }^{35}$. Aun Sharpe, bastante patriótico en su análisis, reconoció que la presencia de navíos holandeses y berberiscos en los mares de Albión fue la motivación para empezar a recaudar el Ship Money después de $1634^{36}$. Asimismo, la confederación irlandesa de la década de 1640 también consiguió numerosos éxitos (se ha identificado al menos 450 presas, y es posible que hubiera muchas más) con sus corsarios en acciones contra los navíos de Bristol y Londres ${ }^{37}$. En diciembre de 1692 el embajador español en Londres informaba que, desde 1689, los comerciantes británicos habían perdido 1.500 navíos debido a los corsarios franceses. Hacia enero de 1695 esta cifra se había aumentado a unos 4.200 merchantmen y 75 navíos de guerra ${ }^{38}$.

de los Austrias. El corso español del Atlántico peninsular en el siglo XVII (1621-1697). Madrid, 1992; RUIZ IBÁÑEZ, J. J. y MONTOJO MONTOJO, V.: Entre el Lucro y la Defensa. Las relaciones entre la Monarquia y la sociedad mercantil Cartagenera. Murcia, 1998.

33. O'DONNELL Y DUQUE DE ESTRADA, H.: «Defensa Militar de los Reinos de Indias. Función militar en las flotas de Indias», en O'DONNELL Y DUQUE DE ESTRADA, H. (ed.): Historia Militar de España. Edad Moderna. I. Ultramar y la Marina. Madrid, 2012, pp. 81-119.

34. RODGER, Safeguard of the Sea..., pp. 390-394.

35. COLLEY, L.: Captives. Britain, Empire and the World, 1600-1850. Londres, 2003; BRADDICK, State Formation..., pp. 209-10; HEBB, D.: Piracy and the English government, 1617-1642. Aldershot, 1994; ANDREWS, Ships, money and politics..., pp. 135-36 y capítulo 7; MATAR, N.: Britain and Barbary, 1589-1689. Gainesville, 2005; operaciones contra los berberiscos en las décadas de 1670 y 1680, RODGER, Command of the Oceans..., pp. 88-92.

36. SHARPE, The Personal Rule of Charles I..., pp. 545, 547, 549-50.

37. MURPHY, Ireland and the War..., pp. 144-45.

38. WILLIAMS, “A Kingdom of such instability...», pp. 376-77.

Ediciones Universidad de Salamanca / @®@@ Stud. his., H. ${ }^{a}$ mod., 41, n. 1 (2019), pp. 231-258 
Nos quedamos, entonces, con la imagen de un estado que no estuvo capacitado para contestar las hegemonías económicas, políticas y militares de Francia, Holanda y la Monarquía Hispánica. Había contradicción total entre la cultura confesional y la organización política, la proyección dinástica y las realidades financieras. Pero, curiosamente, muchos de los estudios del mundo anglosajón que más impacto han tenido en España son libros que no han envejecido bien; estas obras clásicas presentan argumentos bastante excéntricos o ya descartados. En su conjunto, puede ser que partan de la idea de un estado fuerte y agresivo, capaz de poner de manifiesto las ambiciones de los 'puritanos'. Los estudios de Christopher Hill, por ejemplo, fueron muy cuestionados en las décadas de los 70 y 80 por los revisionists. De hecho, hoy en día es muy difícil, si no imposible, utilizar la expresión de revolución puritana, que considera que la causa principal de los disturbios políticos de la década de 1640 fue un programa determinado para imponer una forma rigorosa o estricta de protestantismo en oposición a una tradición anglicana definida. Todo lo contrario, fue la política confesional del rey y del arzobispo de Canterbury (Archbishop), William Laud, la que provocó temores en la teología de las iglesias de Escocia e Inglaterra, derivando en la crisis de 1637-1640 (The Tro Bishops' Wars de 1639 y 1640) y en las maniobras y traiciones de los años 1640-1642. De esta forma, la fracasada guerra contra Escocia en 1640 es el momento decisivo para John Morrill y Charles Carlton ${ }^{39}$. La visión de Hill - de los Puritans como un grupo enfrentado a la Church of England- ya es muy vieja. Como han demostrado Patrick Collinson y otros especialistas, antes de 1625 la teología calvinista dominaba las iglesias de Inglaterra y Escocia, que eran muy conformes con las enseñanzas de las iglesias continentales: en otras palabras, no había una concepción de una iglesia anglicana como algo distinto o apartado a las instituciones y tradiciones eclesiásticas en Holanda, Alemania u otras partes del mundo protestante, salvo con respeto a los obispos y a algunos detalles, como la vestimenta de los $\operatorname{curas}^{40}$. Charles I y el arzobispo Laud fueron los innovadores, los que desafiaron una ortodoxia calvinista con su Arminianism y todo lo que significaba. Es más, hay muy pocos historiadores que vean la revolución como

39. MORRILL, J. S.: The Revolt in the Provinces. The People of England and the Tragedies of War 1630-1648, $2^{\text {a }}$ edición, Londres y Nueva York, 1999, pp. 28-31; MORRILL, y KISHLANSHY, "Charles I...», p. 30 y siguientes; CARLTON, Charles I..., p. 204; Sharpe dedica muchas páginas a demostrar que no hubo una quiebra en las relaciones entre las ciudades de Bristol, York y el gobierno central, SHARPE, The Personal Rule of Charles I..., pp. 625 y ss., esp. p. 643.

40. "Hacia la década de 1620, escribe el profesor Collinson, el puritanismo era un movimiento que disfrutaba del respeto de la sociedad, con raíces muy profundas, y sus líderes eran miembros de la élite». Una obra clásica, COLLINSON, P.: The Religion of Protestants. Oxford, 1983 (citación página 149). 
una consecuencia de la irrupción de fuerzas sociales determinadas, que trataban de imponer el capitalismo y un sistema parlamentario ${ }^{41}$.

Para Hill, la política de la oposición parlamentaria fue reclamar la guerra contra España ${ }^{42}$. Por el contrario, para Russell y Morrill los parlamentos de 1626, 1628 y 1629 estuvieron marcados por conflictos y quejas precisamente porque se celebraron en momentos de guerra (con Felipe IV de España, 1625-1630, y con Louis XIII de Francia, 1627-1629). Otras asambleas, como las de los años 1621 y 1624, fueron mucho más tranquilas, precisamente por tener lugar en tiempos de paz ${ }^{43}$. De la misma forma, puede ser que las obras de Robert Brenner den demasiado protagonismo a los grupos antiespañoles en Londres y exageren su impacto político y cultural durante el reinado de Charles $\mathrm{I}^{44}$. En el contexto de la hegemonía militar, se puede decir que confunde la retórica de un estado imperial y protestante con las realidades de una corona empobrecida, en comparación con sus rivales contemporáneos. No obstante, pocos dudan de que el discurso político estuvo dominado por el temor a una conspiración católica contra las libertades de Inglaterra (the Popish plot) y que, más concretamente, la política del rey en 1639-1640 provocó dudas y sospechas profundas en una buena parte de la nación política ${ }^{45}$.

Los revisionistas insisten en que el problema principal que tuvo que afrontar Charles I fue la falta de recursos, que frustró constantemente sus intentos de impulsar en sus tres reinos una conformidad política, social, moral y religiosa. Sin duda, Irlanda y Escocia fueron claves en el desencadenamiento de la guerra civil. En este contexto, se puede ver su reinado dentro del marco de una monarquía compuesta y hablar de las guerras de religión de los tres reinos - es decir de un fenómeno profundamente británico, y no puramente inglés ${ }^{46}$.

No se puede negar que el sistema político inglés estaba basado en conceptos de extrema complejidad. En unos momentos, el monarca reinaba por encima de la ley; en otros, la ley existía claramente por encima del rey. Todo dependía del contexto: hablar de las instituciones, del papel del Parlamento o de las limitaciones del poder

41. Para estudios generales, se han consultado: CARLTON, Charles I...; SMITH, A. G. R.: The Emergence of a National State. The Commonwealth of England 1529-1660. $2^{\mathrm{a}}$ ed., Londres y Nueva York, 1997; SHARPE, J. A.: Early Modern England. A Social History, 15501760. Londres y Nueva York, 1987, pp. 12-31. Sharpe es muy contundente en sus declaraciones anti-Marxistas y anti-Whig.

42. HILL, C.: The Century of Revolution 1603-1714, $2^{\mathrm{a}}$ ed., Wokingham, 1980, pp. 47-50, 52-53, 54-55.

43. RUSSELL, Parliaments and English Politics..., passim.

44. BRENNER, R.: Merchants and Revolution: commercial change, political conflict and London's overseas traders, 1550-1663. Princeton, 1993.

45. Por ejemplo, véase MORRILL y KISHLANSHY, «Charles I»..., passim.

46. En su última obra, el profesor Russell puso gran énfasis en los acontecimientos en Irlanda y Escocia, RUSSELL, The Fall of the British Monarchies..., passim. 
real es bastante complicado, ya que los derechos de la corona se entendían dentro de una interpretación histórica que ofrecía múltiples ambigüedades y contradicciones ${ }^{47}$. Cómo no, el proceso de Charles I en enero 1649 demostró explícitamente las contradicciones y complicaciones en esta cultura política, sobre todo porque el rey, que antes había intentado gobernar como si él, como monarca, estuviera por encima de la ley, decidió presentarse como el protector de la misma y, como tal, el defensor de los derechos y propiedades de sus súbditos ${ }^{48}$.

Si no existían causas a largo plazo políticas, sociales ni confesionales en la guerra civil que estalló en 1642, los revisionistas (sobre todo el profesor Russell) echaron toda la responsabilidad en la persona del rey. Charles I fue el autor del desastre que le sobrevino: él, y solo él, tuvo la culpa en el estallido de la guerra civil. Más concretamente, los revisionistas insisten en que su política de imponer el libro común de oraciones (Common Prayer Book) le llevó a un conflicto contra los escoceses presbiterianos que el gobierno inglés no fue capaz de manejar. Las dos guerras de obispos (The Two Bishops' Wars, de 1639 y 1640), con el intento por parte del rey de movilizar un ejército, solo empeoraron una situación sumamente complicada (un ejército escocés vino a ocupar las provincias del norte durante el verano de 1640, algo que no sirvió precisamente para tranquilizar a los ingleses). Las finanzas del gobierno tuvieron que afrontar la «huelga de los contribuyentes» (the Taxpayers' Strike), lo que hizo inevitable la convocatoria del Parlamento en 1640.

Estas tensiones llevaron al rey a tomar unas decisiones catastróficas cuando se enfrentó a las quejas del Parlamento, en 1640, y al pleito contra el conde de Strafford, por parte de John Pym (1584-1643) y los líderes de una facción parlamentaria (mayo de 1641). A lo largo de ese año, el grupo en torno a Pym intentó forzar una revolución política contra las instituciones del estado Stuart, que concluyó en la Grand Remonstrance de noviembre de $1641^{49}$. Por si eso fuera poco, le sobrevino la rebelión de los católicos de Irlanda en el otoño de 1641, un acontecimiento que provocó un intenso conflicto entre el rey y los líderes del Parlamento para controlar las milicias de Inglaterra. En ese momento, había una profunda desconfianza por parte de Pym, muchos delegados y algunos nobles ilustres (como Northumberland, Essex, Warwick y Bedford), en la palabra e intenciones del rey. Esta crisis desembocó en el fracasado intento de detener a los cinco diputados en enero de 1642, un acto de autoinmolación por parte del rey que llevó directamente a las primeras acciones de guerra en Kingston-upon-Hull, en abril de 1642, y a la declaración de

47. BRADDICK, M.: State Formation in Early Modern England, c.1550-1700. Cambridge y Nueva York, 2000, p. 242, (citando a G. Burgess); SHARPE, The Personal Rule of Charles I..., p. 929 y ss.

48. CARLTON, Charles I..., capítulo 29, esp. pp. 349-50.

49. MORRILL y KISHLANSHY, «Charles I»..., p. 32 y ss. 
hostilidades por parte del rey en Nottingham, en agosto, a pesar de los intentos de la mayoría de la nobleza y gentry provincial en mantener la neutralidad y así evitar la penuria de una guerra civil ${ }^{50}$.

Aun así, tan tarde como octubre de 1648, la mayoría de los diputados en la Casa de los Comunes (House of Commons) no quería acabar con la vida del monarca, sino que su intención era forzarlo a firmar un acuerdo y dejarlo en el trono con solo un recorte superficial en sus múltiples poderes. Pero el ejército, comandado por Oliver Cromwell y sus compañeros, decidió que era imposible confiar en la palabra del rey. La mala fe de Charles I, su sinfín de maniobras, engaños y artimañas con los escoceses y facciones dentro de Westminster, que derivaron en la segunda guerra civil en el verano de 1648, convencieron a Cromwell y sus compañeros de que el rey no era un hombre de honor, que seguiría manipulando y conspirando contra ellos hasta que triunfara. En definitiva, Cromwell y los generales decidieron acabar con su vida antes de que el monarca lo hiciera con ellos ${ }^{51}$. Fue su única opción. Pero, para cumplir tal decisión, fue necesario utilizar el ejército para controlar los Commons. Así se hizo el 6 de diciembre 1648, con la exclusión de los diputados que se oponían al proceso de Charles I (Pride's Purge). La imagen de una revolución en defensa de los derechos del Parlamento no encuadra con las realidades históricas: lo que hay son maniobras entre facciones y grupos para afianzar su posición y, en diversas circunstancias, proteger su vida dentro de un escenario cada vez más hostil y aun mortífero. Los grandes principios cayeron víctimas de los cálculos políticos.

En esta línea hay que mencionar la contribución de Kevin Sharpe, recientemente fallecido, que intentó absolver totalmente a Charles I de cualquier culpa en el estallido de la guerra civil. Según este autor, lo que le sobrevino fue una serie de desencuentros o accidentes muy desafortunados que nadie habría podido prever y que interrumpieron coyunturas en las que la política estaba dando beneficios en la forma de nuevos y muy elevados ingresos, que permitirían el establecimiento de una armada nueva, potente, profesional y estrechamente ligada a la corona y, por lo tanto, a la res pública52. Para el profesor Sharpe, el rey fue esencialmente una víctima de la mala suerte, ya que sus decisiones y políticas eran muy conformes con

50. SMITH, Emergence..., capítulo 34

51. MORRILL y KISHLANSHY, «Charles I...», pp. 47-49.

52. La idea de una revolución naval - el nacimiento de una nueva armada profesional, vinculada a la corona y dedicada al servicio de la nación - se presenta en THRUSH, A.: «Naval finance and the origins and development of ship money», en FISSEL, M. C. (ed.): War and Government in Britain, 1598-1650. Manchester, 1991, pp. 133-162; ANDREWS, K. R.: Ships, money and politics, p.158; HORNSTEIN, Restoration Navy..., pp. 12-13, 264; DAVIES; J. D.: Gentlemen and Tarpaulins. The officers and men of the Restoration Navy. Oxford, 1991.

Ediciones Universidad de Salamanca / 요 Stud. his., H. ${ }^{a}$ mod., 41, n. 1 (2019), pp. 231-258 
las tradiciones de la corona y como monarca demostró ser un hombre diligente y trabajador. El rey mártir fue, sobre todo, un hombre de principios, de honor y orden ${ }^{53}$.

En 2007, John Adamson presentó los orígenes de la guerra como la obra de una junta de nobles que formaban una conspiración con la intención de imponer en Inglaterra el modelo de una república aristocrática. En su esquema o plan, Inglaterra sería otra Venecia, el rey nada más que un dux. Los nobles actuaron así convencidos de que el programa de Charles I era construir una nueva corona imperial en las islas británicas, asimilando Escocia e Irlanda a un estado autocrático y anglo-céntrico (una ambición que hizo muy poco para tranquilizar los ánimos en Edimburgo o Dublín). Charles I fue, para Adamson, un gran innovador: según él, es llamativo que the First Bishop's War de 1639 fuera la primera campaña, desde el año 1323, en la que la corona se embarcó sin primero buscar una subvención de Parlamento. Aún más, pone énfasis en el hecho de que la política de Strafford en 1640 fue formar una alianza con Madrid, algo que indicaba una actitud innovadora y arbitraria - esto fue, para los rebeldes, prueba definitiva de la conspiración papal (popish plot) y de las ambiciones nefastas de los consejeros del rey ${ }^{54}$.

En cuanto a la figura de Oliver Cromwell, quizás la primera observación tiene que ser la del M. S. Anderson, quien consideró que el gobierno europeo que más se parecía a una dictadura militar fue el de Inglaterra después de $1645^{55}$. El fracaso de la república (la restauración de la casa de Stuart en 1660) se explica fácilmente por la realidad subyacente de que el régimen de Cromwell fue sostenido puramente por la fuerza del ejército. "Todos los datos constatan que cualquier consulta libre a la comunidad [en la década de los 1650] habría demostrado que existía un consenso aplastante a favor de la restauración de la monarquía Stuart $\rangle^{56}$. El Lord Protector y su régimen actuaron con escaso - a veces, sin ningún - concepto de vigilancia parlamentaria o de moderación constitucional. Convencido de que él y sus compañeros eran los servidores de Dios, Cromwell tuvo aún menos respeto por la institución del Parlamento que Charles I. En este sentido, el gobierno de la Commonwealth y Protectorate fue precisamente lo contrario a la situación política posterior a 1660 y durante el siglo XVIII, cuando el papel de Parlamento fue clave como base de la confianza en el estado como prestatario. En otras palabras, el secreto de Gran Bretaña después de 1688 y durante el Setecientos fue precisamente que había rechazado la metodología de Cromwell y su régimen - se puede decir,

53. Véase su conclusión emotiva a favor del rey, SHARPE, The Personal Rule of Charles I..., esp. p. 954.

54. ADAMSON, J.: The Noble Revolt. The Overthrow of Charles I. Londres, 2007, esp. «Prologue», pp. 4, 6, 19, 142 y ss.

55. ANDERSON, M. S.: War and Society in Europe of the Old Regime. Stroud, 1989, p. 61.

56. UPTON, A.: «Politics», en BERGIN, J. (ed.): The Short Oxford History of Europe. The Seventeenth Century. Oxford y Nueva York, 2001, p. 93. 
su revolución militar-, organizado a través de un ejército capaz de impulsar su voluntad sobre esa godly nation.

En este sentido, hay que destacar los argumentos proporcionados por P. G. M. Dickson, John Brewer y, más recientemente, Steve Pincus, de que los cambios decisivos se efectuaron durante los últimos años del siglo, con las adaptaciones políticas, confesionales y culturales que se originaron en la revolución de 1688. Para el profesor Pincus, la transformación de 1688-1689 no fue, en ningún sentido, un accidente: todo lo contrario, fue la consecuencia de una revolución popular que fue capaz de destronar un régimen autoritario y con muchos recursos militares ${ }^{57}$. En cuanto a la historia financiera, el profesor Dickson demostró que la clave fue la fundación del Banco de Inglaterra (Bank of England) en 1694, que inauguró una deuda pública basada en un consolidado mercado al que se acudió para financiar la política mercantil y militar expansiva. Es decir, que el momento determinante en la historia de Gran Bretaña fue la asunción del poder por parte de un rey holandés, William III (1689-1702), y la implantación de un modelo e ideas provenientes de Ámsterdam. Para Pincus, lo decisivo fue no solo el banco y sistema de préstamos, sino el nuevo programa Whig de la nación, un pueblo tan progresista en su política interior como agresivo en defensa de sus intereses exteriores. Se trató, en sus sentidos culturales y políticos, de una revolución burguesa. Eso sí, hay todo un debate sobre la identidad política del nuevo régimen: 1688 fue, para J. C. D. Clarke, el triunfo de un estado confesional, es decir, una cultura política exclusivamente protestante y extremadamente conservadora ${ }^{58}$. La idea de un pueblo tolerante, comercial y liberal, difundida por J. H. Plumb - el gran historiador Whig del siglo XX - en sus celebradas obras y las de sus discípulos, sigue siendo un tema de discusión ${ }^{59}$.

Aquí llega la posible comparación. Es evidente que las guerras del siglo XVII supusieron un peso enorme sobre Madrid y París, Nápoles, Venecia, Viena y Constantinopla. El problema fundamental para el gobierno de España en el siglo XVIII fueron precisamente las deudas de la monarquía absolutista de los Habsburgo y de Felipe V y Carlos III y la herencia de una clase privilegiada - véase, por ejemplo,

57. Para este párrafo, PINCUS, S.: 1688. The First Modern Revolution. Nueva Haven y Londres, 2009 (citación sobre el triunfo de la burguesía, pp. 483, 485); BREWER, Sinerws of Power..., passim; DICKSON, Financial Revolution in England..., passim.

58. CLARKE, J. C. D.: English Society, 1688-1832: Ideology, Religion and Politics During the Ancien Régime. Cambridge, 2000.

59. INNES, J.: «Jonathan Clark, Social History and England's 'Ancien Régime», Past y Present, 115, 1987, pp. 165-200; PLUMB, J. H.: The Growth of Political Stability in England 1675-1725. Londres, 1967; CANNADINE, D.: «Historians in the 'liberal hour': Lawrence Stone and J.H. Plumb revisited», Historical Research, 75, 2002, pp. 316-54.

Ediciones Universidad de Salamanca / @®@@ Stud. his., H. ${ }^{a}$ mod., 41, n. 1 (2019), pp. 231-258 
PHILLIP WILLIAMS

¿UN PUEBLO IGNORANTE DE SU DEBER? EL 'ESTADO CONFESIONAL' DE INGLATERRA

Y LAS LIMITACIONES ESTRATÉGICAS EN LA ÉPOCA DE CHARLES I Y OLIVER CROMWELL

las obras de Francisco Andújar y Rafael Torres Sánchez ${ }^{60}$. Si buscamos una explicación para el fracaso de las reformas en París después de 1715, parece claro (como el profesor Rowlands ha sugerido recientemente) que el peso de las deudas reales, múltiples enajenaciones y asientos dudosos firmados durante las últimas guerras del reinado de Louis XIV imposibilitaron cualquier intento de sanear las finanzas del estado ${ }^{61}$. Es decir, que la ventaja que tuvo Londres en la época de las Luces fue precisamente la ausencia de un estado militar en los siglos anteriores, algo que le permitió evitar las deudas a los banqueros, los arrendadores de impuestos, la venalidad, la manipulación de la moneda y los mecanismos financieros desestabilizadores que se hicieron usuales.

Los esfuerzos para superar las interpretaciones ortodoxas - absolutismo, revolución militar, mercantilismo - nos han proporcionado un panorama innovador sobre el estado europeo del siglo de oro ${ }^{62}$. Pero, puede ser, que el derrumbe de viejas interpretaciones no haya conseguido borrar la imagen de Inglaterra como un país agresivo y expansivo, cuando la realidad es que la armada fue la causa de crisis repetitivas a lo largo del siglo, con consecuencias profundas y extremamente desequilibrantes para Londres. Otras tradiciones historiográficas tampoco quedan inmunes al revisionismo. La interpretación de que el mundo atlántico fuera el decisivo teatro de la guerra naval, por ejemplo, no encaja bien con lo que sabemos de las limitaciones estratégicas de naval power y la situación de las finanzas de la corona de Inglaterra bajo los Stuart ${ }^{63}$. La Gran Armada de 1588 también parece distinta cuando tenemos en cuenta la disparidad enorme entre los ingresos y desembolsos de Felipe II y Elizabeth. La fracasada empresa de Cádiz en 1625 puede ser otra

60. BREWER, Sinews of Power...,passim; ANDÚJAR CASTILLO, F.: Los militares en la España del siglo XVIII: Un estudio social, Granada, 1991; TORRES SÁNCHEZ, R.: El precio de la guerra. El Estado fiscal-militar de Carlos III, (1779-1783). Madrid, 2014; BONNEY, R.: "The rise of the fiscal state in France, 1500-1914», en YUN-CASALILLA, B. y O'BRIEN, P.K. (eds.): The Rise of Fiscal States. A Global History, 1500-1914, Cambridge, 2012, pp. 93-110; DAUNTON, M.: «The politics of British taxation, from the Glorious Revolution to the Great War», en ibid, pp. 111-142.

61. ROWLANDS, G.: The Financial Decline of a Great Power: War, Influence and Money in Louis XIV's France. Oxford et al, 2012, passim.

62. Existe todo un debate en torno al concepto de 'mercantilismo' en la época moderna: probablemente la (inmensa) mayoría de los especialistas del mundo anglosajón votarían a favor de abandonar el concepto. Véase la reseña de Andrew McDiarmid de la obra de MAGNUSSEN, L.: The Political Economy of Mercantilism. Londres, 2015, disponible en https://www.history. ac.uk/reviews/review/1993; una interpretación muy innovadora, PINCUS, S.: «Rethinking mercantilism: Political Economy, the British Empire, and the Atlantic World in the Seventeenth and Eighteenth Centuries», The William and Mary Quarterly, 69/1, 2012, pp. 3-34.

63. Para una interpretación de la época 1560-1620, WILLIAMS, P.: Empire and Holy War in the Mediterranean. The Galley and Maritime Conflict between the Habsburgs and Ottomans. Londres, 2014, capítulo 10.

Ediciones Universidad de Salamanca / అ@@ Stud. his., H. ${ }^{a}$ mod., 41, n. 1 (2019), pp. 231-258 
PHILLIP WILLIAMS

¿UN PUEBLO IGNORANTE DE SU DEBER? EL 'ESTADO CONFESIONAL' DE INGLATERRA

Y LAS LIMITACIONES ESTRATÉGICAS EN LA ÉPOCA DE CHARLES I Y OLIVER CROMWELL

campaña que demuestra que, para Londres, la guerra contra un poder continental era el camino directo a una crisis doméstica. Si la guerra era difícil, los beneficios de la paz resultaban evidentes. Sin entrar en profundidad, sería posible citar un buen número de obras que insisten en la colaboración entre los mercantes de Inglaterra y Castilla - o, si se prefiere, entre los comerciantes de España y Gran Bretaña - y la actuación de las redes comerciales (estudios, por ejemplo, de $\mathrm{M}^{\mathrm{a}}$ Carmen Saavedra Vázquez, María del Carmen Lario de Oñate, Óscar Recio Morales y el profesor Alloza), sin tener en cuenta todos los mercantes irlandeses, holandeses y franceses que estaban activos en Sevilla durante el siglo de oro $^{64}$. Es más, el énfasis sobre el «comercio con el enemigo» ha sido un elemento importante en la historiografía de los últimos años ${ }^{65}$.

En conclusión, parece claro que hubo una transformación en la capacidad guerrera del estado inglés en el siglo XVII y que esta fue clave para los éxitos administrativos y navales de la centuria siguiente. Pero esta revolución esconde la situación bajo Charles I, cuando Inglaterra contó con una corona comparativamente pobre y una armada muy limitada como instrumento de estrategia naval. Otros argumentos ya asentados - que el Parlamento no era una institución decisiva; que el Commons estuvo dividido por facciones, no ideologías; que la cultura mayoritaria en la Iglesia de Inglaterra era el Calvinismo - sirven para matizar este famoso

64. SAAVEDRA VÁZQUEZ, M. C.: «El comercio marítimo de Baiona en la segunda mitad del siglo XVI», Obradoiro de Historia Moderna, 17, 2008, pp. 179-209; ALLOZA APARICIO, Á.: Europa en el Mercado Español. Mercaderes, represalias y contrabando en el siglo XVII. Salamanca, 2006; DÍAZ BLANCO, J. M.: Así trocaste tu gloria. Guerra y comercio colonial en la España del siglo XVII. Valladolid y Madrid 2012, esp. pp. 268-76, 280-281; LARIO DE OÑATE, M. C.: «Irlandeses en el Cádiz del s. XVIII: ciudad de acogida y oportunidades», Ateneo: revista cultural del Ateneo de Cádiz, 14, 2014, pp.93-100. Una visión global de los inmigrantes se presenta en RECIO MORALES, O.: «Los extranjeros y la historiografía modernista», Cuadernos de Historia Moderna. Anejos, 10, 2011, (Ejemplar dedicado a: Los Extranjeros y la Nación en España y la América española) pp. 33-51.

65. PARDO MOLERO, J. F.: «Mercaderes, Frailes, Corsarios y Cautivos. Intercambios entre el Reino de Valencia y el Norte de África en la Primera Mitad del Siglo XVI», en KAISER, W. (ed.): Le commerce des captifs. Les intermédiaires dans l'échange et le rachat des prisonniers en Méditerranée, XVe-XVIIIe siècle. Roma, 2008, pp. 165-192; ALONSO ACERO, B.: «Trenes de avituallamiento en las plazas españoles de Berbería», en GARCÍA HERNÁN, E. y MAFFI, D. (eds.): Guerra y Sociedad..., vol. II. pp. 739-66; MARTÍN CORRALES, E.: Comercio de Cataluña con el Mediterráneo musulmán (siglos XVI-XVIII). El comercio con los «enemigos de la fe». Barcelona, 2001; BLANES ANDRÉS, R.: Valencia y el Magreb. Las relaciones comerciales maritimas (1600-1703). Barcelona, 2010; MONTOJO MONTOJO, V.: «Las redes mercantiles de los comerciantes de Alicante y Cartagena en relación a Orán en la segunda mitad del siglo XVII», en BUNES IBARRA, M. A. y ALONSO ACERO, B. (eds.): Orán. Historia de la Corte Chica. Madrid, 2011, pp. 223-241; en este contexto, véase también TRIVELLATO, F., HALEVI, L. y ANTUNES, C. (eds.): Religion and Trade. Cross-Cultural Exchanges in World History, 1000-1900. Oxford, 2014.

Ediciones Universidad de Salamanca / @®@@ Stud. his., H. ${ }^{a}$ mod., 41, n. 1 (2019), pp. 231-258 
PHILLIP WILLIAMS

¿UN PUEBLO IGNORANTE DE SU DEBER? EL 'ESTADO CONFESIONAL' DE INGLATERRA

Y LAS LIMITACIONES ESTRATÉGICAS EN LA ÉPOCA DE CHARLES I Y OLIVER CROMWELL

concepto de excepcionalism y subrayar las similitudes con otros países europeos. En este contexto parece oportuno enfatizar que un rey holandés implantó un sistema financiero que le daría a Londres la posibilidad de una nueva estrategia global. En otras palabras, una forma de hegemonía puede ser también saber cuándo tomar prestadas ideas e instituciones de otros pueblos europeos.

\section{BIBLIOGRAFÍA}

ADAMSON, J.: The Noble Revolt. The Overthrow of Charles I. Londres, Weidenfeld and Nicolson, 2007.

ANDERSON, P.: Lineages of the Absolutist State, Londres, New Left Books, 1974.

ANDÚJAR CASTILLO, F.: Los militares en la España del siglo XVIII: Un estudio social, Granada, Universidad de Granada, 1991.

ALONSO ACERO, B.: "Trenes de avituallamiento en las plazas españoles de Berbería», en MAFFI, D. y GARCÍA HERNÁN, E. (eds.): Guerra y Sociedad en la monarquía hispánica: politica, estrategia y cultura en la Europa moderna (1500-1700). 2 vols, Madrid, Laberinto, vol. II, pp. 739-66.

ALLOZA APARICIO, Á.: Europa en el Mercado Español. Mercaderes, represalias y contrabando en el siglo XVII. Salamanca, Junta de Castilla y León, 2006.

ALLOZA APARICIO, Á.: Diplomacia caníbal. España y Gran Bretaña en la pugna por el dominio del mundo, 1638-1660. Madrid, Biblioteca Nueva, 2015.

AMIRELL, S. E. y MÜLLER L. (eds.): Persistent Piracy. Maritime Violence and StateFormation in Global Historical Perspective. Basingstoke y Nueva York, McMillan, 2014.

ANDERSON, M. S.: War and Society in Europe of the Old Regime, Stroud, Alan Sutton Publishing, 1998.

ANDREWS, K. A.: Ships, money and politics. Seafaring and naval enterprise in the reign of Charles I. Cambridge, Cambridge University Press, 1991.

ARCHER, I. W.: «The Burden of Taxation on Sixteenth-Century London», The Historical Journal, 44/3, 2000, pp. 599-627.

BEIK, W.: Absolutism and Society in Seventeenth-Century France. State Power and Provincial Aristocracy in Languedoc. Cambridge, Cambridge University Press, 1985.

BÉLY, L.: La société des princes. XVIe-XVIIIe siècle. Paris, Fayard, 1999.

BERGIN, J. (ed.): The Short Oxford History of Europe. The Seventeenth Century. Oxford y Nueva York, Oxford University Press, 2001.

BLACK, J.: A military revolution? Military change and European society 1550-1800. Londres, Red Globe Press, 1991.

BLACK, J.: The British seaborne empire. Nueva Haven, Yale University Press, 2004.

BLANES ANDRÉS, R.: Valencia y el Magreb. Las relaciones comerciales maritimas (1600-1703). Barcelona, Bellaterra, 2010.

BONNEY, R.: "The rise of the fiscal state in France, 1500-1914», en YUN CASALILLA, B. y O'BRIEN, P. K. (eds.): The Rise of Fiscal States. A Global History, 1500-1914. Cambridge, Cambridge University Press, 2012, pp. 93-110.

Ediciones Universidad de Salamanca / @®@@ Stud. his., H. ${ }^{a}$ mod., 41, n. 1 (2019), pp. 231-258 
PHILLIP WILLIAMS

¿UN PUEBLO IGNORANTE DE SU DEBER? EL 'ESTADO CONFESIONAL' DE INGLATERRA

Y LAS LIMITACIONES ESTRATÉGICAS EN LA ÉPOCA DE CHARLES I Y OLIVER CROMWELL

BRADDICK, M.: «The Early Modern English State and the Question of Differentiation, from 1550 to 1700», Comparative Studies in Society and History, 38/1, 1996, pp. 92-111.

BRADDICK, M.: «State formation and social change in early modern England: a problem stated and solutions suggested», Social History, 16/1, 1991, pp. 1-17.

BRADDICK, M.: «An English Military Revolution?», The Historical Journal, 36/4, 1993, pp. 965-975.

BRADDICK, M.: State Formation in Early Modern England, c.1550-1700. Cambridge, Nueva York et al, Cambridge University Press, 2000.

BREWER, J.: The Sinews of Power. War, Money and the English State 1688-1783. Nueva York, Alfred A. Knopf, 1989.

BRENNER, R.: Merchants and Revolution: commercial change, political conflict and London's overseas traders, 1550-1663. Princeton, Princeton University Press, 1993.

CANNADINE, D.: «Historians in the "liberal hour": Lawrence Stone and J. H. Plumb revisited», Historical Research, 75, 2002, pp. 316-54.

CAPP, B.: Cromwell's Navy. The Fleet and the English Revolution. Oxford, Oxford University Press, 1989.

CARLTON, C.: Charles I. The Personal Monarch, segunda edición, Londres y Nueva York, Routledge, 1995.

CLARKE, J. C. D.: English Society, 1688-1832: Ideology, Religion and Politics During the Ancien Régime. Cambridge, Cambridge University Press, 2000.

COLLEY, L.: Captives. Britain, Empire and the World, 1600-1850. Londres, Pimlico, 2003.

COLLEY, L.: Britons. Forging the Nation 1707-1837. $2^{\text {a }}$ edición, Nueva Haven, Yale University Press, 2009.

COLLINS, J.: Classes, Estates and Order in Early Modern Brittany. Cambridge, Cambridge University Press, 1994.

COLLINS, J.: The State in Early Modern France. Cambridge et al, Cambridge University Press, 1995.

COLLINSON, P.: The Religion of Protestants. Oxford, Oxford University Press, 1983.

CUTTICA, C. y BURNESS, G. (eds.): Monarchism and Absolutism in Early Modern Europe. Londres, Pickering and Chatto, 2012.

DAVIES; J. D.: Gentlemen and Tarpaulins. The officers and men of the Restoration Navy. Oxford, Oxford University Press, 1991.

DAUNTON, M.: «The politics of British taxation, from the Glorious Revolution to the Great War», en YUN-CASALILLA, B. y O'BRIEN, P. K. (eds.): The Rise of Fiscal States. A Global History, 1500-1914. Cambridge, Cambridge University Press, 2012, pp. 111-142.

DÍAZ BLANCO, J. M.: Así trocaste tu gloria. Guerra y comercio colonial en la España del siglo XVII. Valladolid y Madrid, Instituto Universitario de Historia SimancasMarcial Pons, 2012.

DICKSON, P. G. M.: The Financial Revolution in England: A Study in the Development of Public Credit, 1688-1756. Londres, Macmillan, 1967.

Ediciones Universidad de Salamanca / అ@@ Stud. his., H. ${ }^{a}$ mod., 41, n. 1 (2019), pp. 231-258 
PHILLIP WILLIAMS

¿UN PUEBLO IGNORANTE DE SU DEBER? EL 'ESTADO CONFESIONAL' DE INGLATERRA

Y LAS LIMITACIONES ESTRATÉGICAS EN LA ÉPOCA DE CHARLES I Y OLIVER CROMWELL

DUCCHARDT, H. y ASCH, R. G. (eds.): El absolutismo (1550-1700), ¿un mito?: revisión de un concepto historiográfico clave. Madrid, Idea Books, 2000.

DUFFY, M. (ed.): The military revolution and the state 1500-1800. Exeter, University of Exeter Press, 1980.

ELLIOTT, J. H.: Empires of the Atlantic World: Britain and Spain in America 1492-1830. Nueva Haven, Yale University Press, 2006.

FERNÁNDEZ NADAL, C. M., La politica exterior de la monarquía de Carlos II. El Consejo de Estado y la Embajada en Londres (1665-1700). Gijón, AIFA Ateneo Jovellanos, 2008.

FLORISTÁN IMÍZCOZ, A.: «Neoforalimso, nuevos fueros y conquistas. Navarra en la Monarquía de Carlos II», en GARCÍA GARCÍA, B. J. y ÁLVAREZ-OSSORIO ALVARINO, A. (eds.): Vísperas de Sucesión. Europa y la Monarquía de Carlos II. Madrid, Fundación Carlos de Amberes, 2015, pp. 81-107.

FISSELL, M. C.: «English Amphibious Warfare, 1587-1656: Galleons, Galleys, Longboats and Cots», en TRIM, D. J. B. y FISSEL, M. C. (eds.): Amphibious Warfare 1000-1700. Commerce, State Formation and European Expansion. Leiden, Brill, 2006, pp. 217-261.

GARCÍA HERNÁN, E. y LARIO DE OÑATE, M. C. (eds.): La presencia irlandesa durante las Cortes de Cádiz en España y América, 1812. Política, Religión y Guerra. Valencia, Albatros, 2013.

GREENGRASS, M. (ed.): Conquest and Coalescence. The Shaping of the State in Early Modern Europe. $2^{\mathrm{a}}$ ed., Londres, Hodder Education Publishers, 1991.

HALE, J. R.: War and Society in Renaissance Europe 1450-1620. $2^{\mathrm{a}}$ ed., Stroud, Sutton Publishing, 1998.

HALE, J. R.: The Civilisation of Europe in the Renaissance. Londres, HarperCollins, 1993.

HEBB, D.: Piracy and the English government, 1617-1642. Aldershot, Scholar Press, 1994.

HENSHALL, N.: The Myth of Absolutism: Change and Continuity in Early Modern European Monarchy. Londres, Taylor and Francis, 1992.

HILL, Ch.: The Century of Revolution 1603-1714. $2^{\mathrm{a}}$ ed., Wokingham, Van Nostrand Reinhold, 1980.

HORNSTEIN, S. R.: The Restoration Navy and English Foreign Trade, 1674-1688: A Study in the Peacetime Use of Sea Power. Aldershot, Scholar Press, 1991.

HOYLE, R. W. (ed.): The Estates of the English Crown, 1558-1640. Cambridge, Cambridge University Press, 1992.

INNES, J.: «Jonathan Clark, Social History and England's 'Ancien Regime'», Past and Present, 115, 1987, pp. 165-200.

JAMES, A.: The Origins of French Absolutism, 1598-1661. Londres, Routledge, 2006.

KENNEDY, P.: The Rise and Fall of British Naval Mastery. Londres, Penguin, 2001.

KISHLANSKY, M.: A Monarchy Transformed. Britain 1603-1714. Londres, Penguin Allen, 1996.

LAVERY, B.: Empire of the Seas. The Remarkable Story of How the Navy Forged the Modern World. Londres, Conway, 2012.

Ediciones Universidad de Salamanca / @®@@ Stud. his., H. ${ }^{a}$ mod., 41, n. 1 (2019), pp. 231-258 
PHILLIP WILLIAMS

¿UN PUEBLO IGNORANTE DE SU DEBER? EL 'ESTADO CONFESIONAL' DE INGLATERRA

Y LAS LIMITACIONES ESTRATÉGICAS EN LA ÉPOCA DE CHARLES I Y OLIVER CROMWELL

LARIO DE ONATE, M.A C.: «Irlandeses en el Cádiz del s. XVIII: ciudad de acogida y oportunidades», Ateneo: revista cultural del Ateneo de Cádiz, 14, 2014, pp. 93-100.

MACKAY, R.: The Limits of Royal Authority. Resistance and Obedience in SeventeenthCentury Castile. Cambridge, Cambridge University Press, 2007.

MAFFI, D. y GARCÍA HERNÁN, E. (eds.): Guerra y Sociedad en la monarquía bispánica: politica, estrategia y cultura en la Europa moderna (1500-1700). 2 vols., Madrid, Laberinto, 2006.

MARTÍN CORRALES, E.: Comercio de Cataluña con el Mediterráneo musulmán (siglos XVI-XVIII). El comercio con los «enemigos de la fe. Barcelona, Bellaterra, 2001.

MATAR, N.: Britain and Barbary, 1589-1689. Gainesville, University Press of Florida, 2005.

DE MESA, E.: The Irish in the Spanish Armies in the Seventeenth Century. Woodbridge, Boydell Press, 2014.

MONTOJO MONTOJO, V.: «Las redes mercantiles de los comerciantes de Alicante y Cartagena en relación a Orán en la segunda mitad del siglo XVII», en BUNES IBARRA, M. Á. y ALONSO ACERO, B. (eds.): Orán. Historia de la Corte Chica, Madrid, Laberinto, 2011, pp. 223-241.

MORRILL, J. S.: Cheshire 1630-1660: County Government and Society during the English Revolution. Oxford, Oxford University Press, 1974.

MORRILL, J. S.: The Revolt in the Provinces. The People of England and the Tragedies of War 1630-1648. $2^{a}$ ed., Londres y Nueva York, Addison Wesley Longman, 1999.

MORRILL, J. S. y KISHLANSKY, M. A.: «Charles I», Dictionary of National Biography, Oxford, 2004, disponible en: https://doi.org/10.1093/ref:odnb/5143.

MOUSNIER, R.: The Institutions of France under the Absolute Monarchy. Chicago, Chicago University Press, 1979.

MURPHY, E.: Ireland and the War at Sea, 1641-1653. Londres, Royal Historical Society, 2012.

NIEVAS, F.: «La forma de guerra en el absolutismo», Cuadernos de Marte, 0, 2010, pp. 9-32.

O'BRIEN, P. K. y HUNT, P. A., «The rise of a fiscal state in England, 1485-1815», Historical Research, 66/160, 1993, pp. 129-176.

O’DONNELL Y DUQUE DE ESTRADA, H.: «Defensa Militar de los Reinos de Indias. Función militar en las flotas de Indias", en O'DONNELL Y DUQUE DE ESTRADA, H. (ed.): Historia Militar de España. Edad Moderna. I. Ultramar y la Marina. Madrid, Laberinto y Ministerio de Defensa, 2012, pp. 81-119.

OTERO LANA, E.: Los corsarios españoles durante la decadencia de los Austrias. El corso español del Atlántico peninsular en el siglo XVII (1621-1697). Madrid, Museo Naval, 1992.

PARDO MOLERO, J. F.: La defensa del imperio. Carlos V, Valencia y el Mediterráneo. Madrid, Sociedad Estatal para la Conmemoración de los Centenarios de Felipe II y Carlos V, 2000.

PARDO MOLERO, J.F.: «Mercaderes, Frailes, Corsarios y Cautivos. Intercambios entre el Reino de Valencia y el Norte de África en la Primera Mitad del Siglo XVI», en KAISER, W. (ed.): Le commerce des captifs. Les intermédiaires dans l'échange et

Ediciones Universidad de Salamanca / @@@ Stud. his., H. ${ }^{a}$ mod., 41, n. 1 (2019), pp. 231-258 
PHILLIP WILLIAMS

¿UN PUEBLO IGNORANTE DE SU DEBER? EL 'ESTADO CONFESIONAL' DE INGLATERRA

Y LAS LIMITACIONES ESTRATÉGICAS EN LA ÉPOCA DE CHARLES I Y OLIVER CROMWELL

le rachat des prisonniers en Méditerranée, XVe-XVIIIe siècle. Roma, École Française de Rome, 2008, pp. 165-192.

PARKER, G.: The Military Revolution. Military Innovation and the Rise of the West, 1500-1800. Cambridge, Cambridge University Press, 1988.

PARROTT, D.: Richelieu's Army. War, Government and Society in France, 1624-1642. Cambridge, Cambridge University Press, 2001.

PARROTT, D.: «France's War against the Habsburgs, 1624-1659: the Politics of Military Failure», en MAFFI, D y GARCÍA HERNÁN, E. (eds.): Guerra y Sociedad en la monarquía hispánica: política, estrategia y cultura en la Europa moderna (1500-1700). 2 vols, Madrid, Laberinto, 2006, vol. I, pp. 31-48.

PARROTT, D.: The Business of War: Military Enterprise and Military Revolution in Early Modern Europe. Cambridge, Cambridge University Press, 2012

PÉREZ TOSTADO, I.: Anglo-Spanish Relations During the English Civil Wars. Londres, IB Tauris (en prensa).

PLUMB, J. H.: The Growth of Political Stability in England 1675-1725. Londres, Humanities Press International, 1967.

PINCUS, S.: 1688. The First Modern Revolution. Nueva Haven y Londres, Yale University Press, 2009.

PINCUS, S.: «Rethinking mercantilism: Political Economy, the British Empire, and the Atlantic World in the Seventeenth and Eighteenth Centuries», The William and Mary Quarterly, 69/1, 2012, pp. 3-34.

RECIO MORALES, O.: España y la pérdida de Ulster: Irlanda en la estrategia política de la Monarquía hispánica (1602-1649). Madrid, Laberinto, 2003.

RECIO MORALES, O.: Ireland and the Spanish Empire, 1600-1825. Dublín, Four Courts Press, 2010.

RECIO MORALES, O.: «Los extranjeros y la historiografía modernista», Cuadernos de Historia Moderna. Anejos, 10, 2011 (Ejemplar dedicado a: Los Extranjeros y la Nación en España y la América española), pp. 33-51.

ROBERTS, M.: «The Military Revolution, 1560-1660», en ROGERS, C. J. (ed.): The Military Revolution Debate. Readings on the Military Transformation of Early Modern Europe. Boulder Colorado, Westview, 1995, pp. 13-36.

RODGER, N. A. M.: The Safeguard of the Sea. A Naval History of Britain. Volume One 660-1649. Londres, W. Norton and Company, 1997.

RODGER, N. A. M.: The Command of the Oceans. A Naval History of Britain, 16491815. Londres, W. Norton and Company, 2004.

ROGERS, C. J. (ed.): The Military Revolution Debate. Readings on the Military Transformation of Early Modern Europe. Boulder Colorado, Westview, 1995.

ROSEVEARE, H.: The Financial Revolution 1660-1760. Londres, Taylor and Francis, 1991.

ROWLANDS, G.: The Dynastic State and Army under Louis XIV. Royal Service and Private Interest, 1661 to 1701. Cambridge, Cambridge University Press, 2002.

ROWLANDS, G.: «Moving Mars: the Logistical Geography of Louis XIV’s France», French History, 25, 2011, pp. 492-514.

Ediciones Universidad de Salamanca / @®@@ Stud. his., H. ${ }^{a}$ mod., 41, n. 1 (2019), pp. 231-258 
PHILLIP WILLIAMS

¿UN PUEBLO IGNORANTE DE SU DEBER? EL 'ESTADO CONFESIONAL' DE INGLATERRA

Y LAS LIMITACIONES ESTRATÉGICAS EN LA ÉPOCA DE CHARLES I Y OLIVER CROMWELL

ROWLANDS, G.: The Financial Decline of a Great Power: War, Influence and Money in Louis XIV's France. Oxford et al, Oxford, Oxford University Press, 2012.

RUIZ FERNÁNDEZ, O.: England and Spain in the Early Modern Era. Londres, IB Tauris, (en prensa).

RUIZ IBÁÑEZ, J. J. y MONTOJO MONTOJO, V.: Entre el Lucro y la Defensa. Las relaciones entre la Monarquía y la sociedad mercantil Cartagenera. Murcia, Real Academia Alfonso el Sabio, 1998.

RUIZ IBÁÑEZ, J. J. (ed.): Las milicias del rey de España. Sociedad, politica e identidad en las Monarquias Ibéricas. Madrid, FCE, Red Columnaria, 2009.

RUSSELL, C.: «Parliament and the king's finances», en RUSSELL, C. (ed.): The Origins of the English Civil War. Londres, Palgrave, 1973, pp. 91-116.

RUSSELL, C.: Parliaments and English Politics 1621-1629. Oxford, Oxford University Press, 1979.

RUSSELL, C.: The Fall of the British Monarchies 1637-1642. Oxford, Oxford University Press, 1991.

SAAVEDRA VÁZQUEZ, M. C.: «El comercio marítimo de Baiona en la segunda mitad del siglo XVI», Obradoiro de Historia Moderna, 17, 2008, pp. 179-209.

SANZ CAMAÑES, P.: Los ecos de la Armada. España, Inglaterra y la estabilidad del Norte. Madrid, Silex, 2013.

SHARPE, J. A.: Early Modern England. A Social History, 1550-1760. Londres y Nueva York, Routledge, 1987.

SHARPE, K.: The Personal Rule of Charles I. Nueva Haven y Londres, Yale University Press, 1992.

SMITH, A. G. R.: The Emergence of a National State. The Commonwealth of England 1529-1660. $2^{\mathrm{a}}$ ed., Londres y Nueva York, Longman, 1997.

STARKEY, D. J. y MCCARTHY, M.: «A Persistent Phenomenon: Private Prize-Taking in the British Atlantic World c.1540-1856», en AMIRELL, S. E. y MÜLLER L. (eds.): Persistent Piracy. Maritime Violence and State-Formation in Global Historical Perspective. Basingstoke y Nueva York, McMillan, 2014, pp. 131-151.

STERN, P. J.: The Company State. Corporate Sovereignty and the Early Modern Foundations of the British Empire in India. Oxford et al, Oxford University Press, 2011.

THOMAS, K.: The Ends of Life. Roads to Fulfilment in Early Modern England. Oxford y Nueva York, Oxford University Press, 2009.

THRUSH, A.: «Naval finance and the origins and development of ship money», en FISSEL, M. C. (ed.): War and Government in Britain, 1598-1650. Manchester, MUP, 1991, pp. 133-162.

TORRES SÁNCHEZ, R.: El precio de la guerra. El Estado fiscal-militar de Carlos III, (1779-1783). Madrid, Marcial Pons Editorial, 2014.

TRIVELLATO, F., HALEVI, L. y ANTUNES, C. (eds.): Religion and Trade. CrossCultural Exchanges in World History, 1000-1900. Oxford, Oxford University Press, 2014.

Ediciones Universidad de Salamanca / @®@@ Stud. his., H. ${ }^{a}$ mod., 41, n. 1 (2019), pp. 231-258 
PHILLIP WILLIAMS

¿UN PUEBLO IGNORANTE DE SU DEBER? EL 'ESTADO CONFESIONAL' DE INGLATERRA

Y LAS LIMITACIONES ESTRATÉGICAS EN LA ÉPOCA DE CHARLES I Y OLIVER CROMWELL

UPTON, A.: «Politics», en BERGIN, J. (ed.): The Short Oxford History of Europe. The Seventeenth Century. Oxford y Nueva York, 2001, pp. 80-111.

WERNHAM, R. B.: "Amphibious Operations and the Elizabethan Assault on Spain's Atlantic Economy», TRIM, D. J. B. y FISSEL, M. C. (eds.): Amphibious Warfare 1000-1700. Commerce, State Formation and European Expansion. Leiden, Brill, 2006, pp. 181-215.

WHEELER, J. S.: The Making of a World Power. War and the Military Revolution in Seventeenth Century England. Stroud, Sutton Publishing, 1999.

WHITE, L.: «Strategic Geography and the Spanish Habsburg Monarchy's Failure to Recover Portugal, 1640-1668», The Journal of Military History, 71/2, 2007, pp. 373-409.

WILLIAMS, P.: «'A Kingdom of such instability and of such a strange form of government.' Irish privateers, Spanish ambassadors and the perception of England and the English, 1688-1697», en GARCÍA HERNÁN, E. y LARIO DE OÑATE, M.C. (eds.): La presencia irlandesa durante las Cortes de Cádiz en España y América, 1812. Política, Religión y Guerra. Valencia, Albatros, 2013, pp. 363-381.

WILLIAMS, P.: Empire and Holy War in the Mediterranean. The Galley and Maritime Conflict between the Habsburgs and Ottomans. Londres, IB Tauris, 2014.

YATES, F. A.: Astrea: The Imperial Theme in the Sixteenth Century. Londres, Pimlico, 1975.

Ediciones Universidad de Salamanca / 요 Stud. his., H. ${ }^{a}$ mod., 41, n. 1 (2019), pp. 231-258 